Publicación semestral. ISSN 2215-4906

Volumen 80 - Número 2

Enero - Junio 2021

\title{
Las heterotopías reivindicativas y contestatarias en la producción fotográfica de Adriana Bustos
}

\author{
The Vindictive and Contestatory Heterotopias \\ in Adriana Bustos' Photography Production
}

Giselle Hidalgo Redondo

Dorde Cuvardic García

\section{(c) (i) $($ )}

Esta obra está bajo una licencia Creative Commons Reconocimiento-No comercial-Sin Obra Derivada 


\title{
Las heterotopías reivindicativas y contestatarias en la producción fotográfica de Adriana Bustos
}

\author{
The Vindictive and Contestatory Heterotopias \\ in Adriana Bustos' Photography Production
}

\author{
Giselle Hidalgo Redondo ${ }^{1}$ \\ Universidad de Costa Rica \\ Costa Rica \\ Dorde Cuvardic García ${ }^{2}$ \\ Universidad de Costa Rica \\ Costa Rica
}

Recibido: 29 de mayo de 2019 Aprobado: 9 de enero de 2020

\begin{abstract}
Resumen
El presente trabajo se centra en la denuncia social de la artista contemporánea argentina Adriana Bustos; en particular, la explotación socioeconómica sufrida por América Latina desde la colonia. Sus textos visuales muestran las relaciones ocultas entre acontecimientos y tiempos divergentes. Realiza esta convergencia espacio-temporal en sus heterotopías artísticas, que muestran su cosmovisión a través de un entramado que designa como su versión no lineal de la historia. La exploración de su obra estará enfocada desde la aproximación teórica de la heterotopía de Michel Foucault.

Palabras claves: explotación; heterotopía; temporalidad; espacio; historia; colonialismo

1 Coordinadora de Acción Social, Sede del Sur, Universidad de Costa Rica (UCR). Máster en Administración y Dirección de Empresas con énfasis en Finanzas por la UCR. ORCID: 0000-00020791-5073. Correo electrónico: giselle.hidalgoredondo@ucr.ac.cr

2 Docente e investigador de la Escuela de Filología, Lingüística y Literatura de la Universidad de Costa Rica. Doctor en Periodismo y Ciencias de la Comunicación por la Universidad Autónoma de Barcelona. ORCID: 0000-0002-6448-9058. Correo electrónico: dorde.cuvardic@ucr.ac.cr
\end{abstract}


Las heterotopías reivindicativas y contestatarias en

Dossier

la producción fotográfica de Adriana Bustos

\begin{abstract}
This article is centered in the social criticism done by the Argentinian contemporary artist Adriana Bustos. Particularly, on the socioeconomic exploitation that Latin America has suffered since colony. Her visual texts show hidden relationships between events and dissimilar times. This time-space divergence is shown through her artistic heterotopic, which displays her world view within a framework of images and texts, designated by Bustos as her non-lineal version of history. The exploration of her artistic work will be focused on the theoretical approach found in Michel Foucault's heterotopic.
\end{abstract}

Key Words: explotation; heterotopic; temporality; space; history; colonialism 


\section{Introducción}

"Me obsesiona encontrar una manera de representar el tiempo y las posibles relaciones secretas entre un evento y otro". (Adriana Bustos citada en Machete Galería, 2018, párr. 4).

El arte contemporáneo cuestiona profundamente nuestra cosmovisión del mundo. Una obra de arte contemporánea pretenderá, de alguna manera, ajustarse a una propuesta ideológica a través de la narrativa de su creador. Su responsabilidad recaerá en ser una voz de alerta y un portavoz del compromiso social. El público espectador, durante este proceso, no solo responderá cognitivamente, sino también emotivamente a través de la furia, el asco, la burla, el miedo, la tristeza o la felicidad ${ }^{3}$. De esta manera, las producciones artísticas instan al espectador a experimentar o vivenciar emociones que le confronten consigo mismo y con su imaginario cotidiano. El artista contemporáneo siente malestar con su entorno y se compromete socialmente a arremeter con furia contra las ideologías hegemónicas.

Desde las coordenadas sociológicas del arte contemporáneo, el presente trabajo estará enfocado en la cosmovisión de la artista argentina Adriana Bustos, que requiere, a su vez, comprender su representación de la historia de América Latina desde perspectivas periféricas y subalternas. Su producción artística se enfoca en visibilizar las continuidades y conexiones que se dan en la historia latinoamericana, más allá de las diferencias temporales y espaciales. En su estudio, Adriana Bustos identifica acontecimientos y procesos lejanos en el tiempo -incluso en el espacio-, pero que ella los correlaciona con acontecimientos y procesos del presente. En consecuencia, logra entretejer otra historia, polémica esta vez. Como lo menciona en la entrevista sostenida con Adriano Pedrosa, su análisis contempla la reflexión desde problemas sociales como el narcotráfico, los recursos naturales, el mercado de sustancias ilegales, pasando por asuntos económicos, estadísticos o geopolíticos, su perspectiva sobre el paisaje o el tema del deseo en el sujeto humano (citado en Liprandi, 2013). Con el uso de diversas técnicas artísticas crea espacios heterotópicos, que resultan de la simbiosis crítica entre diversos tiempos y contextos sociales, lejanos cronológica y espacialmente, pero similares en las implicaciones ideológicas que expresan. Desde la crítica académica, su producción artística, más particularmente Imago Mundi VI, VII, VIII, IX, X y

3 Como lo plantea Heinich (2017, p. 66), parafraseando a Maurizio Cattelan, "ya no es tanto la búsqueda de la belleza lo que caracteriza el enfoque artístico como la búsqueda de emociones, de sensaciones, de arrebatos". 
XI, una serie de acrílicos, ha sido analizada e interpretada por María Cristina Ares (2016; 2018). Esta última investigadora analiza estos acrílicos como una resignificación crítica de la cartografía tradicional, en la que se intersectan conocimiento y poder. Bustos propone una imaginaria en la que se reconfiguran los espacios de la cartografía histórica y la designación de los lugares, que pasan a estar ocupados, por ejemplo, por nombres de pensadores periféricos o marginales. Por ende, la artista argentina realiza un trabajo de collage que ilumina las relaciones de poder creadas por el discurso de la modernidad, siguiendo la estela de Walter Benjamin (Ares, 2018, p. 780).

\section{La heterotopía en la obra de Adriana Bustos}

En esta aproximación adicional a la obra de Adriana Bustos, usaremos como recurso conceptual la heterotopología de Foucault, planteada como la ciencia que:

Tendría por objeto esos espacios diferentes, esos otros lugares, esas impugnaciones míticas y reales del espacio donde vivimos. Esta ciencia estudiaría no las utopías, puesto que hay que reservar ese nombre a lo que no tiene realmente ningún lugar, sino las heterotopías, los espacios absolutamente diferentes (Foucault, 2010, p. 21).

Entre estas impugnaciones se encuentran las nuevas configuraciones espacio-temporales que se crean a través de las producciones artísticas. Martin Jay (2007, pp. 286314), aunque sitúa a Foucault entre aquellos pensadores franceses del siglo XX que se oponían al dominio del ocularcentrismo en Occidente, estaba interesado -precisamente por ese motivo- en problemáticas vinculadas en la visión y el espacio. Evidentemente, la esfera de las heterotopías forma parte de este interés. Michel Foucault introduce su concepción de heterotopía en una conferencia radiofónica de 1966, posteriormente publicada en el texto De los Espacios Otros, en 1984. En este documento plasma su reflexión sobre este concepto como una forma de develar que:

No se vive en un espacio neutro y blanco; no se vive, no se muere, no se ama en el rectángulo de una hoja de papel. Se vive, se muere, se ama en un espacio cuadriculado, recortado, abigarrado, con zonas claras y zonas oscuras, diferencias de niveles, escalones, huecos, protuberancias, regiones duras y otras desmenuzables, penetrables, porosas. Están las regiones de pasaje, las calles, los trenes, los metros; están las regiones abiertas del alto transitorio, los cafés, los cines, las playas, los hoteles, y después están las regiones cerradas del reposo y de la propia casa (Foucault, 2010, p.20). 
En otras palabras, los espacios sociales -y los creados por los juegos de la imaginación, entre ellos los artísticos- no son neutros y objetivos, sino ideológicos y subjetivos. Las heterotopías son aquellos espacios periféricos fuera de la cotidianeidad, de la normalidad. Pueden ser tanto espacios disciplinarios que el poder crea para controlar al sujeto como de espacios carácter lúcido o imaginativo en los que el sujeto puede escaparse y resguardarse momentáneamente del contexto social. Si bien en algunas ocasiones se pueden asociar a los espacios de vigilancia y castigo, como la cárcel y el manicomio, en otras ocasiones se pueden concebir como los lugares en los que se desinhiben las aparentes anomalías sociales y estas últimas se encuentran en zonas de confortabilidad, escape y liberación. Desde este último punto de vista, se podrían identificar las heterotopías como sitios donde convergen transitoriamente las emociones, los deseos, las locuras y las irracionalidades, las cuales contribuyen a revestir, desde el ensueño, nuestro contexto cotidiano.

La creación de las heterotopías permite imaginar otras realidades posibles. El arte y la literatura consiguen crear espacios que terminan volviéndose reales ante la mirada de sus creadores y de sus lectores y espectadores. El mismo Foucoult menciona el arte como una materialización más de las heterotopías. El filósofo francés nos da dos ejemplos, el teatro y el cine:

el teatro hace suceder sobre el rectángulo de la escena toda una serie de lugares que son ajenos unos a otros; es así como el cine es una muy curiosa sala rectangular, en cuyo fondo, sobre una pantalla de dos dimensiones, se proyecta un espacio en tres dimensiones (Foucault, 2010, p.75).

Como podemos apreciar, Foucault considera que la heterotopía, como condición para existir, procede a delimitar un espacio alternativo, un espacio "otro", del contexto social. Es lo que hace toda manifestación artística a través del concepto del marco o encuadre. Por medio de este último signo, de carácter indicial, se pretende indicar que la realidad contenida dentro de sus límites se debe entender como ficción artística: hablamos de la superficie del lienzo, en el caso de la pintura; hablamos de la superficie de la pantalla, en el caso del cine; y hablamos de la superficie tridimensional del escenario, en el caso del teatro.

No quisiéramos dejar de destacar la cercanía estética e ideológica que guarda este concepto de heterotopía con el de cronotopo de Mijail Bajtín (1989). Las heterotopías no son utopías políticas imaginarias, sino utopías localizadas de la vida cotidiana, y coyunturalmente separadas de esta última, tanto espacial como temporalmente. Como precisa Foucault, son lugares que buscan borrar, neutralizar o purificar los espacios de la convivencia 
social cotidiana: "son de alguna manera contraespacios. Los niños conocen perfectamente esos contraespacios, esas utopías localizadas [el destacado es del original]” (2010, p. 20). Algunas de estas heterotopías son creadas por el niño en el marco de las coordenadas espacio-temporales liminares del juego, y ya destacó en su momento Freud, en "El creador literario y el fantaseo" (2012, pp. 124-135), las similitudes existentes entre el trabajo imaginativo del niño y el del artista.

En este artículo proponemos reflexionar sobre el concepto de heterotopía en dos niveles de sentido. En primer lugar, en el ya mencionado párrafo precedente, podemos considerar el arte en general (y la producción artística de Adriana Bustos, en particular) como una heterotopía. El arte es un espacio-otro que plantea anti-normativas, que nos permite reflexionar críticamente sobre la sociedad hegemónica, legitimadora -por el contrario- de espacios normativos. En cambio, el arte contestatario, sea figurativo o no, propone mundos alternativos o imaginarios que escapan, se enfrentan o refutan el mundo normativo. En segundo lugar, podemos afirmar que en las composiciones fotográficas de Adriana Bustos se construyen o representan heterotopías imaginarias, dentro de los cuatro límites del marco. Son nuevos espacios, creados mediante la actualización intertextual o la yuxtaposición de imágenes previamente existentes, y estos nuevos espacios - de carácter contestatariopermiten al espectador reconocer las relaciones de explotación y dominación que todavía guían la convivencia social en América Latina.

Foucault sustenta seis principios básicos sobre las heterotopías en "Espacios diferentes", texto inicialmente publicado como conferencia en 1967, que fueron inicialmente cinco en una conferencia previa, "Las heterotopías", pronunciada en 1966. En el primer principio nos señala que toda sociedad tiene sus heterotopías; en particular, mientras las sociedades primitivas cuentan con "heterotopías de crisis", protagonizadas por individuos en crisis biológicas, como son las casas para las mujeres en época de parto, las sociedades contemporáneas toman su relevo las "heterotopías de desviación", como las cárceles (Foucault, 2010).

En relación con el segundo principio, señala que "cada heterotopía tiene un funcionamiento preciso y estipulado en el interior de la sociedad, y la misma heterotopía, según la sincronía de la cultura en la que se encuentra, puede tener uno y otro funcionamiento" (Foucault, 2010, p. 73), como ocurre con el caso del cementerio. Es decir, las heterotopías están histórica y socialmente situadas. Un tercer principio de la heterotopía radica en el hecho de que "tiene el poder de yuxtaponer en un solo lugar real varios espacios, varios 
emplazamientos que son en sí mismos incompatibles" (Foucault, 2010, p.75). El arte, en general, llega a configurar este tipo de heterotopías, al crear nuevos espacios surgidos del proceso creativo del artista. Dentro de los límites del lienzo (pintura), del escenario (teatro), de la hoja de papel (literatura escrita) o de la pantalla (cine) quedan yuxtapuestos espacios de la imaginación. El cuarto principio está asociado al hecho de que las heterotopías se vinculan a cortes singulares del tiempo, cortes en los que este último se acumula hasta el infinito (como los museos y las bibliotecas), en los que se despliega la temporalidad de la fiesta, o en los que tiene lugar la temporalidad del pasaje, la transformación y la regeneración (como los colegios y los cuarteles) (Foucault, 2010, pp.76-78).

Una quinta cualidad de las heterotopías consiste en el hecho de que cuentan con distintos sistemas de apertura y de cierre que las aísla del espacio circundante, como ocurre con las cárceles, las saunas escandinavas, los prostíbulos o los moteles (Foucault, 2010, pp.78-79). Son espacios que cuentan con su propia frontera, delimitación o marco; este último los distingue del espacio circundante. Es más, a veces el espacio liminal, fronterizo, es la heterotopía. Tanto el espacio ficcional creado por el arte como el espacio de recepción del arte (museos, por ejemplo) también permiten ilustrar este último principio. Las heterotopías encierran el deseo y las aspiraciones de los sujetos, visualizan el ideal y refutan la realidad. ¿Acaso no es este el propósito del Arte? Por último, como sexto rasgo,

tienen, respecto del espacio restante, una función. Esta se despliega entre dos polos extremos. O bien tienen la función de crear un espacio de ilusión que denuncia como más ilusorio todavía todo el espacio real ... O bien, por el contrario, creando otro espacio, otro espacio real tan perfecto, tan meticuloso, tan bien arreglado como el nuestro es desordenado, mal dispuesto y confuso (Foucault, 2010, pp. 79-80).

La primera es una heterotopía de ilusión y encuentra su ejemplo en el prostíbulo; la segunda, de compensación, con el ejemplo de las colonias. Las producciones artísticas pueden cumplir ambas funciones.

\section{La función reivindicativa en la heterotopía en el proyecto 4X4 (2003-2006) de Adriana Bustos: la dignificación del caballo de carga}

Adriana Bustos nos plantea espacios heterotópicos en su producción artística, algunos de ellos reivindicativos, algunos contestatarios. Visibiliza una versión crítica de la historia latinoamericana: yuxtapone procesos sociales del pasado a una contemporaneidad 
igualmente crítica, como si se repitieran -a través de los siglos y de los espacios- las mismas relaciones de sujeción y opresión social. Como resultado, en su producción artística se establecen semejanzas y similitudes simbólicas entre diferentes momentos históricos.

Iniciamos nuestro análisis con la serie "Retratos" (fotografías, 2004), que junto con las series "Primavera" (video experimental, loop, 6 minutos, 2003), "Empotrados" (grafito sobre canvas, 2006) y "Ejemplares" (fotografías, 2006), forma parte de un proyecto mayor, conocido como Proyecto 4X4 (2003-2006). En todas estas series el protagonista es el caballo. La imagen icónica del equino prevalece a lo largo de su producción artística: fotografía, grafito, pintura, mapas cartográficos, videos, instalaciones y otras formas de producción artística.

El contexto social que generó estas series fue la crisis del corralito. La ciudad argentina de Córdoba se encontró sumida, a inicios de la década del 2000, al igual que el conjunto del país, en medio de una crisis social y económica. En estas circunstancias se encontró en auge el oficio de cartonero, que se convirtió, junto con los caballos que empleaban en su trabajo, en protagonista de uno de los proyectos de Adriana Bustos. En su portafolio explica la intención que tuvo al crear esta serie fotográfica, Retratos (2004), la de pensar a los equinos como exiliados en el interior del país: "simulan las fotografías destinadas a los documentos de identidad, de azul-celeste utilizadas para pasaporte y copian la pose de pinturas ecuestres del siglo XVIII destinadas a caballos de pedigrí, para recordar que estos también son 'caballos argentinos' y además nuevos 'habitantes urbanos'” (Bustos, 2018, párr. 3). Más que el cartonero propiamente dicho, la tracción animal (el caballo) empleado en este oficio se convirtió en su centro de atención. Adriana Bustos destaca, con esta serie, que los caballos también realizaron un gran aporte en el proyecto de construcción de la Nación argentina.

El sentido irónico del título de su gran macroproyecto, $4 X 4$, formado por las series "Retratos", "Primavera", "Empotrados" y "Ejemplares", está incentivado por el hecho de que los oficios humanos en los que se emplean animales suelen designar a estos últimos con la expresión "tracción animal", como ocurre también en la minería. La ironía estriba en el hecho de que el cartonero no emplea un automóvil de tracción 4X4 para desplazarse, sino la "tracción animal" de un caballo4. El título $4 X 4$ también alude al hecho de que se trata de 4 series dedicadas a animales de 4 patas.

${ }^{4}$ Recordemos que, en sentido inverso, de la esfera animal a la automovilística, se emplea la metáfora "caballos de potencia". 
El cartonero es aquel tipo social u oficio del espacio público argentino, y en particular cordobés, que se ocupa de recoger cartones y otros productos desechados, mercancías convertidas en residuos por el consumidor, que él se dedica a acopiar y reciclar. Es aquel sujeto que, en otros contextos hispanohablantes, es conocido como trapero, recuperador o buzo. En estas circunstancias, el caballo cartonero es el caballo empleado por el cartonero para cargar con todos los objetos que recoge. Estos últimos son vendidos por este tipo social a la industria del reciclaje. En este contexto, ¿qué intención tiene Adriana Bustos al representar el caballo del cartonero? A través de este proyecto, según Grinstein (19 de marzo de 2011), se cuestionan "dos cosmovisiones, una urbana -alimentada de elevados imaginarios estéticos- y otra ruralizada, pauperizada, hecha carne en ese caballo que es la tracción a sangre de las otras $4 \times 4$, las que se multiplican en las ciudades bajo la forma de carritos de cartoneros" (párr. 2). En el espacio público cordobés se exhibe un fuerte contraste -por yuxtaposición- entre los caballos y los automóviles. A pesar de ocupar un mismo espacio social, connotan opuestos y excluyentes espacios sociales, el de la riqueza, el de la modernidad urbana, y el de la pobreza, el sistema tradicional de vida premoderno.

Imagen 1. Rosario ${ }^{5}$

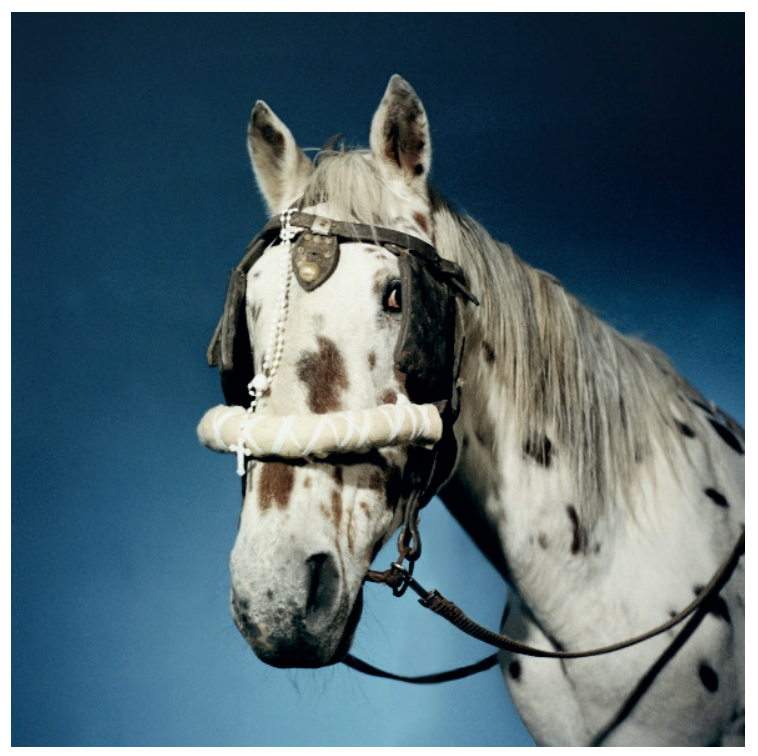

Fuente. Proyecto 4X4 (Bustos, 2018a).

Como ya vimos, "Retratos" implica la resemantización de las fotografías del género del retrato, específicamente del género de la foto de pasaporte. Esta serie tiene por protagonistas a los caballos y yeguas que trabajan junto con sus dueños en el acarreo de cartón y papel en las calles de la ciudad de Córdoba. Podríamos hablar, propiamente, del subgénero del retrato equino. En esta oportunidad, en todo caso, se aleja del género pictórico ecuestre de las carreras de caballos, representadas entre otros por Edgar Degas. En el espacio heterotópico alternativo del retrato equino de Adriana Bustos se utiliza como fondo una tela de color azul cielo, como se

\footnotetext{
${ }^{5}$ Rosario, 2004. Fotografía toma directa / Direct shot photography 90 × 90 cm / 35.4 × 35.4 in Edición.
} 
observa en la Imagen 1, que muestra la fotografía de "Rosario". Retratos muy similares de la misma serie están dedicados a "Moro", "Soñador", "Nena" y "Toro". El encuadre y el fondo utilizados en esta serie son típicos de los retratos tipo pasaporte realizados en estudio, donde el sujeto fotografiado es representado en busto con un fondo azul celeste, para que destaque el rostro. El género del retrato se encuentra asociado tradicionalmente al ser humano, pero en este caso el protagonista es un animal. Desde la serie "Retratos", el caballo -por lo demás, domesticado- queda humanizado, convertido en un actor social por derecho propio, y sometido a las convenciones de la imagen pública de todo actor social. Se refuerza esta imagen singularizada y humanizada del caballo si pensamos que Bustos le otorga un título a esta fotografía, que designa la identidad nominal del caballo. El último queda dignificado y visibilizado en su desempeño de animal de carga, útil para la sociedad, al quedar incorporado en el espacio heterotópico -alternativo- del género fotográfico que hemos decidido llamar retrato equino.

Asimismo, esta pista interpretativa, la dignificación y visibilidad del trabajo del caballo -a la par, sin relación jerárquica, junto con el cartonero- nos la proporciona, además, la propia artista, cuando rememora la pasantía que obtuvo en Londres: "había descubierto que caballos, mulas y burros tenían carnets de identificación en Inglaterra" (Bustos, 2013, p. 36). La artista argentina, frente a la función degradada de simple animal de carga del caballo cartonero, intenta devolverle la dignidad al equino, al facultarle una identidad, representada o expresada con su imagen singularizada, en el espacio heterotópico del retrato. En este caso, la heterotopía fotográfica detenta una función reivindicativa y un nombre propio.

En el Proyecto $4 X 4$ se presenta también una colección de fotografías titulada "Ejemplares", que incluye a equinos cartoneros y a sus dueños, que posan delante de telas, realizadas por la propia Adriana Bustos. Como explica la artista argentina, reproducen pinturas paisajistas del artista cordobés costumbrista Egidio Cerrito, de inicios del siglo $X X$, que representaban el rancho, el pajonal y el páramo en pinturas destinadas a las familias de clase media de la década de 1880; los protagonistas "son caballos cartoneros que posan delante de un fondo que pinté, (a la manera de un fotógrafo de plaza), en un intento utópico de regresarlos al 'campo'” (Bustos, 2018, párr. 6)

La serie fotográfica consta de "Ledezma con Laiza en un Cerrito", "Miguel con Sombra en un Cerrito", "Muñeca en un Cerrito", "Laiza en un Cerrito", "Sombra en un Cerrito", "Barón en un Cerrito" y "Barón en un Cerrito II". En la Imagen 2, que nos muestra la fotografía titulada 
"Miguel con Sombra en un Cerrito", Imagen 2. "Miguel con Sombra en un Cerrito" se procede a una resignificación del retrato ecuestre. Como primera muestra de resemantización, recordemos que en la fotografía de estudio se empleaba un fondo pintado y delante a una familia (el género del retrato familiar dominical). En el presente caso, en cambio, vemos al equino y al cartonero. Como segundo procedimiento de resignificación, recordemos los retratos ecuestres de las monarquías absolutistas. En el caso de Adriana Bustos, a la par -y no subido al animal, como en el caso de los nobles y monarcas- se encuentra el cartonero. En los retratos ecuestres del Príncipe Baltasar

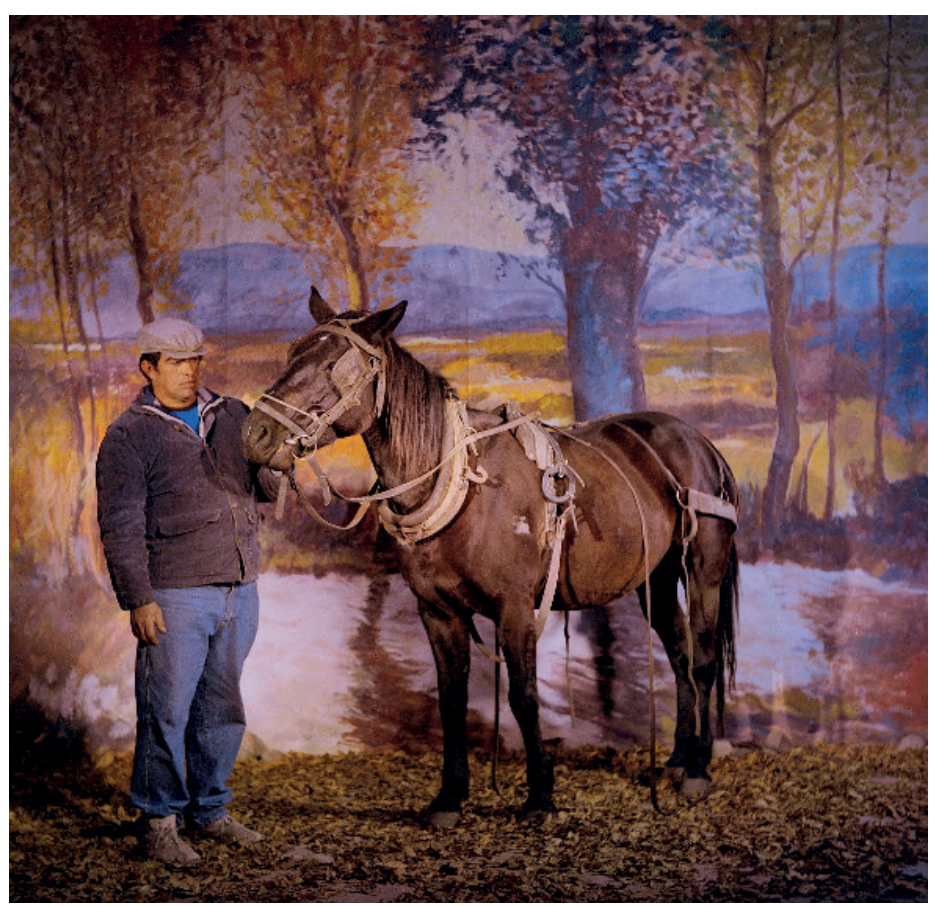

Fuente: Proyecto 4X4 (Bustos, 2018b). Carlos, de Felipe IV y del Conde Duque de Olivares -todos ellos de Velazquez- o en los retratos ecuestres de Carlos I de Inglaterra (1620 y 1633) de Van Dyck, el sujeto monárquico, subido al caballo con el paisaje al fondo, se pretende representar la hegemonía política desde la alegoría de la equitación.

En la fotografía de Bustos, el cartonero está de pie, al lado del caballo, en pie de igualdad con el cartonero, con el paisaje al fondo. Se trata, como vemos, de una democratización del retrato ecuestre de la realeza. En todo caso, debe reconocerse en la representación visual del caballo de las fotografías de Adriana Bustos como lo que es: es un animal domesticado, que cuenta con arnés, anteojera, entre otros aditamentos, y que está al servicio de la actividad del cartonero, al ser animal de carga de los objetos reciclados. Aun así, la heterotopía reivindicativa planteada por Bustos consiste en crear un espacio democrático en el que el caballo queda a la par con el cartonero. Ambos, cartonero y caballo, son trabajadores y realizan su actividad conjuntamente, dignificados en su labor, sin jerarquías laborales. 


\section{La colonialidad de las rutas locales y globales latinoamericanas: la heterotopía de denuncia en "Antropología de la mula" de Prosa del Observatorio}

La relevancia de este proyecto reside en el hecho de que se trata de una muestra compilatoria de 11 años de la producción de la artista que permite mostrar una visión ampliada de la trayectoria de su trabajo. Asimismo, esta colección representa la primera exposición individual de Adriana Bustos en Europa. Se exhibió en el 2017 en el Museo de Arte Contemporáneo de Castilla y León (España). El proyecto Prosa del Observatorio alude a la obra de mismo título de Julio Cortázar, publicada en 1972, "en la que el autor argentino establece correspondencias entre la migración de las anguilas por los ríos europeos y las observaciones nocturnas del maharajá Jai Singh, creador de observatorios astronómicos durante el siglo XVIII en Jaipur y Delhi" (Bustos, 2017, p. 6). Prosa del observatorio es una exposición celebrada en León que incorpora tres series de trabajos expuestos con anterioridad, Antropología de la mula (20072011), ¿Quién dice qué a quién? (2016-2017) y El retorno de lo reprimido (2017).

Las correspondencias que Cortázar expone con la zoología son reinterpretadas en clave social por Bustos. Esta resignificación, en la artista argentina, cuestiona e invita a reflexionar sobre el despojo social, económico, cultural y ambiental que existe en América Latina desde la época de la colonia, como veremos a continuación. A manera de ejemplo, de la exhibición Prosa del Observatorio, se analizarán dos imágenes.

En la Imagen 3 se muestra "Antropología de la Mula". Adriana

Imagen 3. Antropología de la mula.

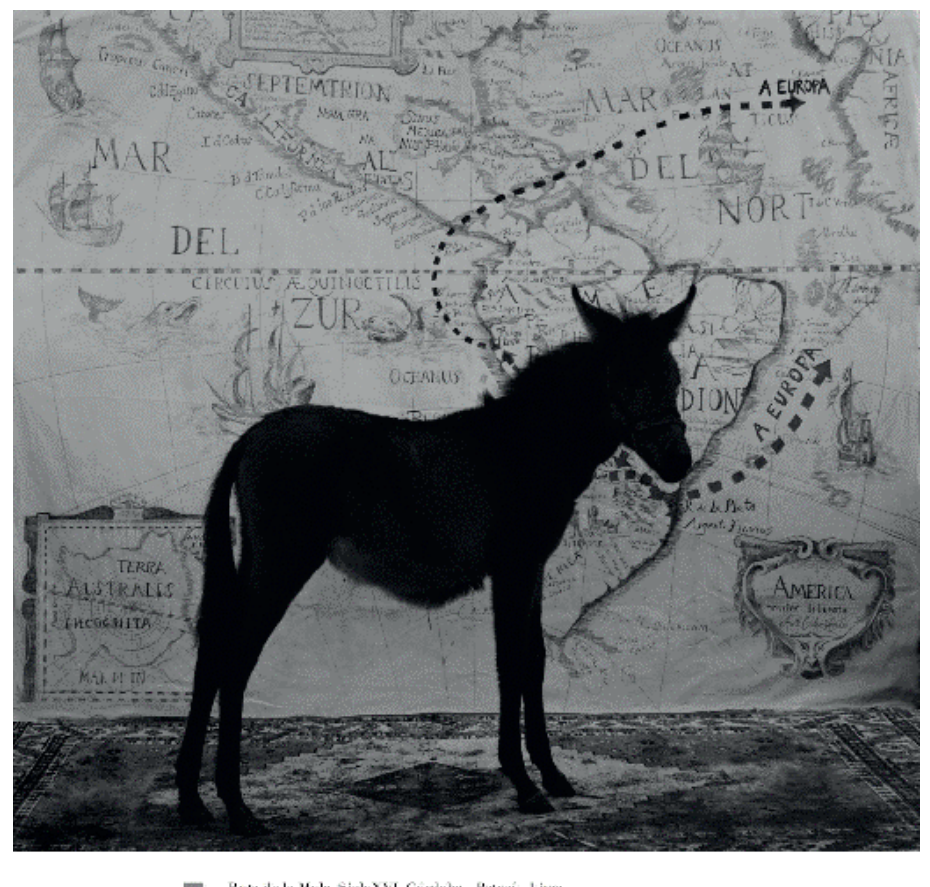

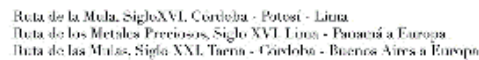

Fuente: Proyecto Antropología de la Mula (Bustos, 2018c). 
Bustos fotografía una mula en primer plano con un mapa al fondo. En el espacio heterotópico cartográfico que ha creado Bustos se expresan las relaciones ideológicas, más allá de la distancia histórica, entre las rutas de explotación de la plata en la colonia y las rutas actuales del narcotráfico. El género discursivo empleado por la artista para representar estas relaciones económicas, constantes a lo largo de la historia centroamericana, es la lámina didáctica, que vemos en las salas de muchos museos y que, en el presente caso, al explicar un proceso, el del comercio transatlántico, incorpora el procedimiento descriptivo de la ruta comercial cartografiada. Es decir, Bustos crea un espacio explicativo que yuxtapone un animal de carga, la mula, y un mapa. A su vez, este último yuxtapone el trazado de tres rutas latinoamericanas que expresan la continuidad histórica de las relaciones de colonialidad de América Latina con Europa, incorporadas como leyendas explicativas debajo de la fotografía. Nos referimos, en primer lugar, a la ruta de la mula, instaurada en el siglo XVI, entre Córdoba, Potosí y Lima. En segundo lugar, a la ruta de los metales preciosos, entre Lima, Panamá y Europa; y, en tercer lugar, a la ruta de las 'mulas' humanas del narcotráfico, en pleno siglo XXI, entre Córdoba, Buenos Aires y Europa. La primera ruta es terrestre; la segunda, marítima; la tercera, aérea. En cualquier caso, las tres expresan relaciones de explotación humana, social y económica entre una periferia y una metrópoli. La colonialidad del poder, a escala global, se ha fundamentado en distintas rutas: la de la esclavitud atlántica, la de los monocultivos, la de las especias o la del narcotráfico. En este sentido, Bustos pretende mostrar las conexiones históricas existentes entre todas estas rutas.

Esta lámina didáctica representa una creación espacial, un punto de encuentro, una heterotopía creada por una artista. Si las heterotopías, como lo menciona Foucault, son "lugares que se oponen a todos los otros, que están destinados de algún modo a borrarlos, a neutralizarlos o a purificarlos" (2010, p. 20), el espacio heterotópico creado por una artista en su producción, de carácter crítico, como es el caso de las series fotográficas de Bustos, tiende a deconstruir la supuesta neutralidad ideológica de los procesos sociales e históricos que muchas veces nos difunden las instituciones hegemónicas. Bustos establece en el mapa dibujado en el fondo un vínculo -invisibilizado desde la colonialidad del saber por las instituciones hegemónicas occidentales- entre las rutas coloniales existentes entre los siglos XVI y el XVIII y las rutas del narcotráfico en los siglos XX y XXI. Dos de las rutas, la primera y la tercera, tienen un punto en común que recae en la figura de la mula. En la primera ruta nos referimos al animal de carga, durante la colonia, y en la tercera a la "mula", al ser humano, animal de acarreo en la economía globalizada del capitalismo. 
La imagen creada por Bustos llega a estructurar un espacio heterotópico, al exhibir las semejanzas ideológicas existentes entre rutas separadas en el tiempo, pero que muestran un mismo proceso histórico: la función de América Latina como una región que exporta materias primas (llámese minerales, productos agrícolas o drogas) y que ocupa un papel subalterno en los procesos económicos del capitalismo globalizador. En su imagen convergen conexiones sociohistóricas y económicas entre el pasado y el presente, al yuxtaponer los trayectos de las mulas y de las "mulas" humanas. Es un espacio-otro, un espacio de denuncia, que logra ver las relaciones de explotación del sistema mercantilista en la colonia y las relaciones de explotación en el capitalismo globalizado.

Si reflexionamos más sobre las implicaciones ideológicas de la mula como animal de carga y de la mula humana como sujeto de carga, veremos que el sujeto subalterno latinoamericano siempre ha estado asociado a este concepto. Como lo define la artista, la mula hace referencia a "aquellas personas, verdaderos correos humanos, que transportan importantes cantidades de cocaína en el estómago a través de la ingesta de cápsulas o en sus cuerpos o equipajes" (Bustos, 2013, p. 7). Son, en cierta medida, mulas de carga para el capitalismo. Recordemos, por ejemplo, a los tamemes centroamericanos de la colonia, a los silleros decimonónicos, como los existentes en Colombia, que transportaban a los viajeros europeos en los sitios escarpados de las montañas, o a los linieros que trabajaban para la United Fruit Company. La mula que traslada droga a Estados Unidos y Europa es la última versión de una figura que, lamentablemente, metaforiza la sujeción del sujeto latinoamericano a los intereses de la economía mercantilista, primero, y capitalista, posteriormente.

Además, la mula representada en la composición fotográfica, ubicada delante del mapa de las rutas, está completamente a oscuras. Se ha convertido, prácticamente, en un sombreado. Poco falta -excepto por un segmento de su tripa, que tiende al gris- para que este animal se convierta en una simple silueta. El sombreado de la mula se presta a varios significados alegóricos. Por una parte, alude al anonimato de las mulas humanas: no tienen rostro. Para los actores de la narco-geopolítica, estos seres humanos son intercambiables. Si en algún punto de la ruta son apresados por la policía, rápidamente serán repuestos o sustituidos, como lo eran las mulas en las antiguas rutas comerciales, en los centros de abastecimiento. El sombreado también se presta a otro significado alegórico, esta vez circunscrito a la actividad ejercida por la mula: es una actividad ilegal, oculta, realizada en las sombras, frente a las actividades económicas legales, realizadas a plena luz del día. La tripa, que tiende al gris, alude alegóricamente al estómago de la mula humana, donde se oculta la droga. 


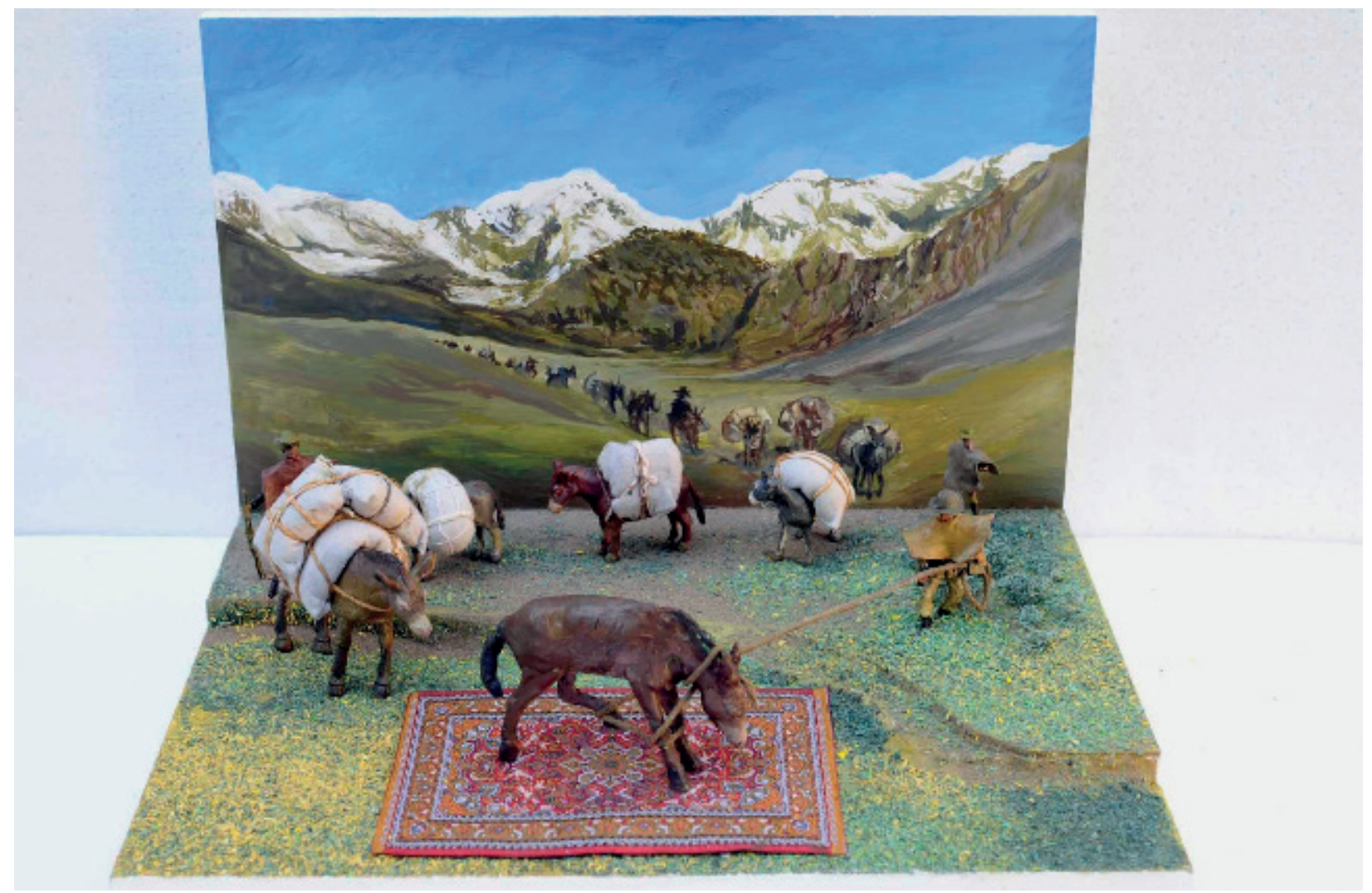

Fuente: Proyecto Antropología de la Mula (Bustos, 2018d).

En la Imagen 4, Adriana Bustos estructura un diorama o teatrillo. En primer plano, muestra un camino transitado por estatuillas de arrieros y sus animales de carga, y en el fondo, la pintura de una montaña andina, en la que aparece representada una caravana de mulas (posiblemente procedente de Córdoba y Salta, la ruta mencionada previamente). Esta caravana se ofrece en dos modalidades de representación: de pintada en dos dimensiones pasa a ser escultórica, en tres dimensiones. También vemos una mula que, aunque está desprovista de su carga y aparejos (sospechamos que se ha desprendido de ellos), está siendo sujetada para que no pueda escapar -volar- en la alfombra mágica colocada bajo sus patas. Además del espacio heterotópico del teatrillo (como arte que ofrece otra realidad), la alfombra es, en este caso, un espacio heterotópico de amplia raigambre cultural, cuya semántica es la posibilidad de otorgar la libertad. La alfombra es el espacio de huida de la opresión, el 
control. Esta metaforización nos recuerda la metáfora del jardín como un tapete, explicada por Foucault:

si se piensa que los tapices orientales eran, en el origen, reproducciones de jardines ... se comprende el valor legendario de los tapices voladores, de los tapices que recorrían el mundo. El jardín es un tapiz donde el mundo en su totalidad viene a consumar su perfección simbólica, y el tapiz es un jardín móvil a través del espacio (Foucault, 2010, p. 25).

La alfombra es un espacio-otro que tiene la posibilidad de llevar a la mula a la libertad. El diorama no ofrece el final de la narrativa mostrada. Si el mulero termina por sujetar a la mula, regresará a su condición de animal de carga, como el resto de las mulas del diorama; si consigue escapar, subida al tapete, será libre. El intertexto es claro: la alfombra voladora de los cuentos de hadas es un espacio heterotópico que nos permite trasladarnos a espacios soñados, vinculados a la libertad.

\section{Conclusiones}

La finalidad de esta exploración por parte de la obra de Bustos nos plantea un desafío importante, el cual se desprende de relacionar su trabajo con líneas filosóficas foucaltianas. Las exposiciones realizadas por Adriana Bustos han mostrado relaciones de opresión históricamente recurrentes en América Latina mediante analogías estructurales. Esta artista argentina realiza una búsqueda de las relaciones ocultas entre los acontecimientos y los procesos históricos latinoamericanos. A través de su práctica artística yuxtapone imágenes en principio incompatibles o sin aparente correlación. Son representaciones distantes en el tiempo y el espacio que, al quedar yuxtapuestas, exhiben sus implicaciones ideológicas.

El arte contemporáneo expresa espacios heterotópicos posibles, ya sea democratizadores ("Retratos" y "Ejemplares", series en las que los caballos se convierten en sujetos ciudadanos), contestatarios ("Antropología de la mula", de Antropología de la mula, al denunciar las relaciones de explotación), o soñadores ("Diorama", de Antropología de la mula, al pensar en un espacio de libertad). La relevancia del quehacer del artista recaerá en crear dispositivos críticos que nos trasladen, como sujetos espectadores, hacia espacios heterotópicos. 


\section{Referencias}

Ares, M. C. (2018). El arte cartográfico contemporáneo. Imago Mundi de Adriana Bustos: desordenando el orden. Actas del I Congreso Internacional de Artes, 777-786. Recuperado de http://www.adrianabustos.com.ar/wp-content/uploads/2018/06/ EL-ARTE-CARTOGRA\%CC\%81FICO-CONTEMPORA\%CC\%81NEO.pdf

Ares, M. C. (2016). Arte cartográfico. Mapas de resistencia: Horacio Zabala y Adriana Bustos. IV Congreso Internacional Artes en Cruce: Constelaciones de sentido, Universidad de Buenos Aires. Recuperado de http://eventosacademicos.filo.uba.ar/index.php/artesencruce/AEIV2016/paper/viewFile/3301/1809

Bajtín. M. (1989). Teoría y estética de la novela. (Capítulo: Las formas del tiempo y del cronotopo en la novela). Madrid: Taurus.

Bustos, A. (2017). Prosa del Observatorio. MUSAC: España. Recuperado de https://musac.es/FOTOS/VISITAS_GUIADAS/Adriana\%20Bustos_gu\%C3\%ADa\%20de\%20 sala_08.17.pdf

Bustos, A. (2018). PROYECTO 4X4. Recuperado de: http://www.adrianabustos.com.ar/ portfolio/proyecto-4-x-4-2003-2006/

Bustos, A. (2018a). Rosario [Fotografía]. PROYECTO 4X4. Recuperado de http://www. adrianabustos.com.ar/portfolio/proyecto-4-X-4-2003-2006/

Bustos, A. (2018b). Miguel con Sombra en un Cerrito [Fotografía]. PROYECTO 4 X 4 [Fotografía]. Recuperado de http://www.adrianabustos.com.ar/portfolio/proyecto-4-x-4-2003-2006/

Bustos, A. (2018c). Antropología de la Mula [Fotografía]. PROYECTO ANTROPOLOGÍA DE LA MULA. Recuperado de http://www.adrianabustos.com.ar/portfolio/antropologia-de-la-mula-2006-2011/

Bustos, A. (2018d). Diorama [Fotografía]. PROYECTO ANTROPOLOGÍA DE LA MULA. Recuperado de http://www.adrianabustos.com.ar/portfolio/antropologia-de-la-mula-2006-2011/

Bustos, A. (2018d). Rosario [Fotografía]. PROYECTO 4 X 4. Recuperado de: http://www. adrianabustos.com.ar/portfolio/proyecto-4-X-4-2003-2006/ 
Las heterotopías reivindicativas y contestatarias en

Dossier

la producción fotográfica de Adriana Bustos

Cortázar, J. (2016). Prosa del Observatorio. Madrid: Alfaguara.

Freud, S. (2012). Obras Completas. Vol. IX. Buenos Aires: Amorrortu.

Foucault, M. (2010). El cuerpo utópico. Las heterotopías. Buenos Aires: Nueva Visión.

Grinstein, E. (19 de marzo de 2011). Mulas y Caballos [Entrada en un blog]. Investigación Museo Caraffa. Recuperado de http://investigacionmuseocaraffa.blogspot. com/2011/03/adriana-bustos.html

Heinich, N. (2017). El paradigma del arte contemporáneo. Estructuras de una revolución artística. Madrid: Editorial Casimiro.

Jay, Martin. (2007). Ojos abatidos. La denigración de la visión en el pensamiento francés del siglo XX. Madrid: Editorial Akal.

Machete Galería. (2018). Directorio Adriana Bustos. Recuperado de http://macheteart.com/ es/adriana-bustos

Liprandi, I. (2013). Adriana Bustos. Recuperado de https://www.academia.edu/26091164/ Adriana_Bustos_Art_works

ESCENA. Revista de las artes, 2021, Vol. 80, Núm. 2 (enero-junio), pp. 152-170 